\title{
(6) OPEN ACCESS \\ Longitudinal study of correlates of modern contraceptive use and impact of HIV care programmes among HIV concordant and serodiscordant couples in Rakai, Uganda
}

\author{
Heena Brahmbhatt, ${ }^{1}$ Fredrick Makumbi, ${ }^{2}$ Tom Lutalo, ${ }^{3}$ \\ Joseph Sekasanvu, ${ }^{4}$ David Serwadda, ${ }^{5}$ Maria J Wawer, ${ }^{6}$ Ronald H Gray ${ }^{7}$
}

For numbered affiliations see end of article.

\section{Correspondence to} Dr Heena Brahmbhatt, Johns Hopkins Bloomberg School of Public Health, E4010, 615 North Wolfe Street, Baltimore, MD 21205, USA; hbrahmbh@jhsph.edu

Received 15 January 2013 Revised 13 May 2013 Accepted 29 June 2013 Published Online First 16 August 2013

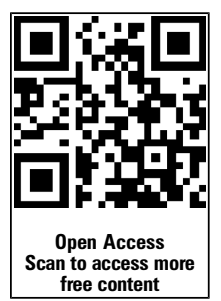

CrossMark

To cite: Brahmbhatt $\mathrm{H}$, Makumbi F, Lutalo T, et al. J Fam Plann Reprod Health Care 2014;40:208-216.

\section{ABSTRACT}

Objective To assess trends and determinants of family planning use and impact of HIV serostatus among couples.

Methods Couples' data were retrospectively linked from cohort surveys in Rakai, Uganda between 1999 and 2011, and were classified by HIV status as concordant (M+F+/M-F-) or serodiscordant ( $\mathrm{M}-\mathrm{F}+/ \mathrm{M}+\mathrm{F}-$ ). HIV care (HIVC) was grouped into three periods, pre-antiretroviral therapy (pre-HIVC) (<2004), HIVC roll-out (20052007) and HIVC scale-up ( $\geq 2008)$. Trends in couple contraceptive use were assessed by chisquare test $\left(\chi^{2}\right)$ for trend, and multinomial logistic regression was used to estimate adjusted odds ratios (ORs) of predictors of contraceptive use.

Results A toal of 6139 couples contributed 13709 observations. Hormonal contraception (HC) use increased over time from $22.9 \%$ to $33.9 \%, p<0.001)$, with significant increases among $\mathrm{M}-\mathrm{F}-(23.2 \%$ to $34.8 \%, p<0.0001)$ and $\mathrm{M}+\mathrm{F}+(20.8 \%$ to $32.2 \%, p=0.0005)$, but not serodiscordant couples. Condom use significantly increased among $\mathrm{M}+\mathrm{F}+(30.3 \%$ to $48.0 \%$, $p<0.001)$ and serodiscordant couples $(24.2 \%$ to $48.7 \%, p<0.001)$, but not among $\mathrm{M}-\mathrm{F}-$ couples. Dual use of $\mathrm{HC}$ and condoms increased over time, irrespective of HIV status. Factors associated with increases in contraceptive use were: higher education, co-resident children, male non-marital relationship and scaled-up HIVC phase.

Enrolment into HIVC was associated with increased $\mathrm{HC}$ and condom use among HIV+ concordant [adjusted OR (adjOR)=3.03; 95\% confidence interval (CI) 1.69-5.44 and adjOR=4.46, 95\% Cl 2.53-7.86, respectively], and serodiscordant couples (adjOR=2.21;95\% Cl 1.25-3.92 and adjOR=4.75; 95\% Cl 2.89-7.82, respectively).

\section{Key message points}

- Few studies examine contraceptive use among couples from longitudinal studies, with most cross-sectional studies focusing on women alone.

- The present study in couples assessed over a 10-year period found that contraceptive use and dual use of hormonal contraception and condoms increased over time.

- Higher education and scaling-up of HIV care services were key determinants of contraceptive use among couples in the present study.

- In settings with overlapping rates of high fertility and HIV infection, integration of HIV and reproductive health services is critical.

Conclusions Use of modern contraception and dual method use increased over time, particularly after enrolment into HIVC. Integration of HIV and reproductive health services is critical for prevention of unwanted pregnancies and HIV infection.

\section{INTRODUCTION}

Sub-Saharan Africa (SSA) has the highest fertility rates in the world. ${ }^{1}$ Low uptake of modern contraceptive methods with high levels of unmet need for family planning (FP) led to high rates of unplanned pregnancies in this region, ${ }^{1}$ with an average total fertility rate (TFR) of 5.1 children per woman in SSA. ${ }^{2}$ In 
Uganda, the TFR is 6.2, with about 755000 unplanned pregnancies per year. ${ }^{3}$ However the recent Demographic and Health Surveys (DHS) show a significant increase in modern contraceptive use from $18 \%$ in $2005 / 2006$ to $26 \%$ in 2011 , and a corresponding decline in the level of unmet need for FP (41\% to $34 \%){ }^{3}{ }^{4}$ In Rakai district, South Western Uganda, similar trends in uptake of modern contraceptives $(33 \%$ to $42 \%)$ and declines in unmet need for FP (35\% to 29\%) have been observed during the same period (Lutalo T, Trends and determinants of unmet need for modern contraceptives in Rakai, Uganda, personal communication, 2012).

These changes occurred in a generalised HIV epidemic. The high rates of HIV infection and fertility suggest that couples in developing countries need protection against HIV and sexually transmitted infections (STIs), as well as protection from unplanned pregnancies through use of effective contraception, including condoms that offer protection from HIV/STIs and pregnancy. It is estimated that 23.5 million people were living with HIV in SSA in 2011, the majority of whom were women of reproductive age. ${ }^{5}$ In Uganda the prevalence of HIV among adults $15-49$ years is $7.1 \%,{ }^{6}$ while in Rakai district it is estimated at $12 \%{ }^{7}$ Effective integration of HIV and reproductive health services is critical in settings with overlapping high rates of fertility and HIV prevalence.

The goal of this study was to examine levels and determinants of modern contraceptive use in a rural, resource-limited setting with high HIV prevalence, and substantial HIV care (HIVC) service provision. Although previous studies have been mainly crosssectional and focused on female respondents only, this longitudinal study over an 11-year period used couples as the unit of analysis, and assessed the determinants of modern contraceptive use by couples' HIV status in Rakai, Uganda.

\section{METHODS}

The Rakai Health Sciences Program (RHSP) has followed individuals aged 15 to 49 years in an open cohort since 1994 in 50 rural villages through the Rakai Community Cohort Study (RCCS), ${ }^{8}$ in Rakai district, South-Western Uganda. Detailed sociodemographic, behavioural and sexual behaviour data were collected annually from consenting participants. Men and women were independently asked questions on the individual's or partner's use of contraception including permanent methods. HIV status was determined from venous blood using two different enzyme immunoassays (Vironostika ${ }^{\circledR}$ HIV-1, OrganonTeknika, Charlotte, NC, USA and Cambridge Biotech, Worcester, MA, USA), with Western blot (HIV-1 WB ${ }^{\circledR}$, Bio-Merieux-Vitek, St Louis, MO, USA) confirmation of all discordant EIAs and all HIV seroconverters.

Participants who wished to know their HIV serostatus received voluntary counselling and testing
$(\mathrm{VCT})^{9}{ }^{10}$ as individuals or couples either in their home or at the RHSP community counselling facilities by a trained counsellor. The HIV counselling discussion included HIV prevention strategies such as abstinence, consistent use of condoms, couple counselling, partner disclosure, FP and prevention of mother-to-child HIV transmission (PMTCT). Free or subsidised condoms were provided to all individuals who wished to have them and referrals were provided for other modern contraceptive methods.

All participants testing HIV-positive were referred for HIVC at 17 RHSP clinics where they were evaluated for antiretroviral therapy (ART) eligibility [CD4 $\leq$ 250 cells $/ \mathrm{mm}^{3}$ or World Health Organization (WHO) Stage IV]. Although basic HIVC has been provided to all HIV-infected individuals, highly active antiretroviral therapy (HAART) has only been available since June 2004 through the President's Emergency Plan for AIDS Relief (PEPFAR). In addition to HAART, other services provided by the expanded HIVC services included FP for prevention of unwanted pregnancies, health and nutrition education, cotrimoxazole prophylaxis, insecticide-impregnated bed nets, and clean water vessels with hypochlorite disinfectant.

For this analysis, couples were the unit of analysis, and were retrospectively linked and categorised as concordantly HIV-negative (M-F-), concordantly HIV-infected $(\mathrm{M}+\mathrm{F}+)$ and discordant (either $\mathrm{M}+\mathrm{F}-$ or $\mathrm{F}+\mathrm{M}-$ ), where $\mathrm{M}$ and $\mathrm{F}$ indicate male and female, respectively. Information was obtained on each form of modern contraception, and injectables, pills and Norplant ${ }^{\circledR}$ were consolidated into one category of hormonal contraception (HC). Couples' use of contraception was categorised as (i) $\mathrm{HC}$ if $\mathrm{HC}$ use was reported by the female partner, (ii) use of condoms alone if mentioned by the male, but without female mention of HC and (iii) none if no modern methods were mentioned by either partner. A couple was coded with uptake of female-controlled method or male-controlled method if there was discrepancy in a couple member's report of a FP method. Dual use was defined as couples reporting concurrent condoms and $\mathrm{HC}$ use.

Covariates considered for the multivariate analysis included female age, duration since female partner receipt of VCT stratified as VCT within 30 days, VCT within 31-182 days, VCT within 183-365 days and VCT $\geq 366$ days prior to interview; couple's education categorised as 'none' if at most one partner had primary education, 'primary' if at most one had postprimary but both had at least primary education, or 'post-primary' if both had post-primary. Co-resident children were categorised as none, one to two, three to five, and six or more. Non-marital partners was defined as a respondent reporting a sexual relationship with someone to whom they were not officially married or in a consensual union either in the past 12 months or ongoing and was categorised as none, or any reported by the female-only, the male only, or 
both. The HIVC periods were categorised as pre-HIVC before 2004, HIVC roll-out (2005-2007) and HIVC scale-up (2008-2011). Other variables controlled for in the multivariate analyses were socioeconomic status (SES) based on the dwelling construction materials, with high SES if modern construction materials (iron/tiles, cement) were used, type of marriage (monogamous or polygamous) and religion.

Trends in the use of contraceptives over the three HIVC care periods were analysed using chi-square $\left(\chi^{2}\right)$ for trend, stratified by the couple's HIV status. To assess determinants of contraceptive use, multinomial logistic regression models were used to estimate odds ratios (ORs), and 95\% confidence intervals (95\% CIs) of $\mathrm{HC}$ use versus no modern methods, or use of condoms for FP versus no modern methods. Adjusted analyses included all variables in the univariate models with $p<0.15$, potential confounders or variables with an $\mathrm{OR} \geq 2.0$ or $\leq 0.5$. We also adjusted for clustering at the couple level, because of multiple observations from the same couples, using sandwich robust standard errors (SEs). We conducted a sub-analysis of couples with at least one HIV+ partner to estimate the effect of enrolment into HIVC by either one or both HIV+ partners. All statistical analyses were done using STATA software package V.12.0 (College Station, TX, USA).

The study was approved by Institutional Review Boards in Uganda (the Scientific and Ethics Committee of the Uganda Virus Research Institute, and the Uganda National Council of Science and Technology), and the USA (Western IRB, Olympia, Washington, and the Johns Hopkins University, School of Public Health).

\section{RESULTS}

A total of 6139 couples contributed 13709 couple observations from the eight annual RHSP survey rounds conducted between March 2000 and June 2011. Of the couples in our analyses, $5083(82.8 \%)$ were concordant HIV-negative, 481 couples $(7.8 \%)$ concordant HIV+, 279 couples (4.5\%) serodiscordant

Table 1 Demographic and use of voluntary counselling and testing and family planning services by couples, stratified by HIV status

\begin{tabular}{|c|c|c|c|c|c|}
\hline Couples' characteristics & $\begin{array}{l}M-F- \\
(n=11566)\end{array}$ & $\mathrm{M}+\mathrm{F}+(n=1033)$ & $M-F+(n=480)$ & $\mathrm{M}+\mathrm{F}-(n=630)$ & $p$ \\
\hline \multicolumn{6}{|l|}{ Average age in years (SD) } \\
\hline Male partner & $34.1(7.0)$ & $35.5(6.3)$ & $34.7(6.7)$ & $36.8(6.5)$ & $<0.001$ \\
\hline Female partner & $28.6(6.7)$ & $30.0(6.1)$ & $29.9(6.4)$ & $30.9(6.7)$ & $<0.001$ \\
\hline \multicolumn{6}{|l|}{ Highest schooling $[n(\%)]$} \\
\hline None & 1008 (8.7) & $118(11.4)$ & $60(12.5)$ & $61 \quad(9.7)$ & \\
\hline Primary & $8917(77.1)$ & $799(77.3)$ & $376(78.3)$ & $500(79.4)$ & $<0.001$ \\
\hline Post-primary & $1641(14.2)$ & $116(11.2)$ & $44 \quad(9.2)$ & $69(11.0)$ & \\
\hline \multicolumn{6}{|l|}{ Non-marital relationships $[n(\%)]$} \\
\hline None & $9200(79.5)$ & $814(78.8)$ & $388(80.8)$ & $487(77.3)$ & \\
\hline Female only & 175 (1.5) & $19(1.8)$ & $15(3.1)$ & $14 \quad(2.2)$ & 0.047 \\
\hline Male or both & $2189(18.9)$ & $200(19.4)$ & $77(16.0)$ & $129(20.5)$ & \\
\hline \multicolumn{6}{|l|}{ Co-resident biological children [n (\%)] } \\
\hline 0 & $867 \quad(7.5)$ & $157(15.2)$ & $82(17.1)$ & $78(12.4)$ & \\
\hline $1-2$ & 3996 (34.5) & $397(38.4)$ & $211(44.0)$ & $204(32.4)$ & $<0.001$ \\
\hline $3-5$ & $5230(45.2)$ & $427(41.3)$ & $166(34.6)$ & $272(43.2)$ & \\
\hline $6+$ & $1473(12.7)$ & $52(5.0)$ & $21(4.4)$ & $76(12.1)$ & \\
\hline \multicolumn{6}{|c|}{ Duration between VCT and interview (days) $[n(\%)]$} \\
\hline No VCT within 30 days & $2056(17.8)$ & $251(24.3)$ & $118(24.6)$ & $118(18.7)$ & \\
\hline $31-182$ & 981 (8.5) & $70(6.8)$ & $44 \quad(9.2)$ & $41(6.5)$ & $<0.001$ \\
\hline $183-365$ & $1901(16.4)$ & $123(11.9)$ & $66(13.8)$ & $99(15.7)$ & \\
\hline $366+$ & $6628(57.3)$ & $589(57.0)$ & $252(52.5)$ & $372(59.0)$ & \\
\hline \multicolumn{6}{|l|}{ Stage of HIV programme roll-out $[n(\%)]$} \\
\hline Pre-HIV & $3610(31.2)$ & $307(29.7)$ & $161(33.5)$ & $228(36.2)$ & \\
\hline Within first 2 years of implementation & $2544(22.0)$ & $217(21.0)$ & 79 (16.5) & $141(22.4)$ & 0.003 \\
\hline $3+$ years after initial implementation & $5412(46.8)$ & $509(49.3)$ & $240(50.0)$ & $261(41.4)$ & \\
\hline \multicolumn{6}{|l|}{ Couple reported FP methods [n (\%)] } \\
\hline None & $5597(48.4)$ & $352(34.1)$ & $204(42.5)$ & $230(36.5)$ & \\
\hline $\mathrm{HC}$ & $3522(30.5)$ & $289(28.0)$ & $118(24.6)$ & $170(27.0)$ & $<0.001$ \\
\hline Condoms & $2447(21.2)$ & $392(37.9)$ & $158(32.9)$ & $230(36.5)$ & \\
\hline
\end{tabular}

FP, family planning; HC, hormonal contraception; HIVC, HIV care; SD, standard deviation; VCT, voluntary counselling and testing. 
where the male was HIV+ and 296 couples (4.8\%) where the female was HIV+.

Table 1 summarises the couples' characteristics by HIV status. The $p$ value in Table 1 is the association between couple HIV status and the various characteristics. HIV serodiscordant couples were significantly more likely to have no or primary education, whereas HIV-negative concordant couples were significantly more likely to have a post-primary education $(p<0.001)$. HIV-positive females $(\mathrm{F}+\mathrm{M}-)$ and males $(\mathrm{F}-\mathrm{M}+)$ in serodiscordant relationships were significantly more likely to report multiple sexual partners $(p<0.001)$. The average number of biological co-resident children was 3.04; this was higher when the female spouse was HIV-negative $(\mathrm{M}-\mathrm{F}-$ or $\mathrm{M}+\mathrm{F}-, p<0.001)$. Overall, receipt of VCT in the past 31 days or more was high, $81.5 \%$; $\mathrm{M}-\mathrm{F}-$ couples $82.2 \%$ and $\mathrm{M}+\mathrm{F}-81.3 \%$; but lower when the female spouse was $\mathrm{HIV}+$ in a concordant $\mathrm{M}+\mathrm{F}+$ $(75.7 \%)$ or serodiscordant $\mathrm{M}-\mathrm{F}+$ couple $(75.4 \%)$.

Overall, use of modern contraceptives was $53.0 \%$ (HC 29.9\% and condoms 23.5\%). The most commonly mentioned methods of modern contraceptives were injectables $(23.1 \%)$, followed by condoms (16.3\%), pills (5.2\%) and Norplant (1.7\%). Condoms use was higher when a couple member was HIV+ $(\mathrm{M}+\mathrm{F}+37.9 \% ; \mathrm{M}-\mathrm{F}+32.9 \% ; \mathrm{M}+\mathrm{F}-36.5 \%)$, relative to $\mathrm{M}-\mathrm{F}-(21.2 \%)$, while injectables were more frequent among $\mathrm{M}-\mathrm{F}-(30.5 \%)$.

Over the three HIVC periods, use of HC significantly increased from $22.9 \%, 31.3 \%$ and $33.9 \%$, respectively $\left(\chi^{2}\right.$ for trend $\left.p<0.001\right)$. These temporal increases were statistically significant in $\mathrm{M}-\mathrm{F}-(23.2 \%$, $31.2 \%$ and $34.8 \%$, respectively; $p<0.001$ ); and $\mathrm{M}+\mathrm{F}$ $+(20.8 \%, 27.6 \%$ and $32.2 \%$, respectively; $p=$ $0.005)$; but not among discordant couples, $(21.3 \%$,

Table 2 Odds ratios of hormonal contraception and condom use among all couples

\begin{tabular}{|c|c|c|c|c|c|c|c|c|}
\hline \multirow[b]{2}{*}{ Parameter } & \multicolumn{4}{|c|}{ Hormonal contraceptives } & \multicolumn{4}{|l|}{ Condoms } \\
\hline & $\begin{array}{l}\text { HC-user/ } \\
\text { total }\end{array}$ & $\begin{array}{l}\text { HC-user/ } \\
\text { total (\%) }\end{array}$ & $\begin{array}{l}\text { UnadjOR } \\
(95 \% \mathrm{Cl})\end{array}$ & $\begin{array}{l}\text { AdjOR* } \\
(95 \% \mathrm{Cl})\end{array}$ & $\begin{array}{l}\text { Condom/ } \\
\text { total }\end{array}$ & $\begin{array}{l}\text { Condom/ } \\
\text { total }(\%)\end{array}$ & $\begin{array}{l}\text { UnadjOR } \\
(95 \% \mathrm{Cl})\end{array}$ & $\begin{array}{l}\text { AdjOR* } \\
(95 \% \mathrm{Cl})\end{array}$ \\
\hline \multicolumn{9}{|l|}{ Education } \\
\hline None & 194/984 & 19.7 & 1.00 & 1.00 & $263 / 1053$ & 25.0 & 1.00 & 1.00 \\
\hline Primary & $3160 / 8111$ & 39.0 & $2.6 \quad(2.12-3.18)$ & $2.2(1.78-2.72)$ & $2481 / 7432$ & 33.4 & $1.51(1.24-1.83)$ & $1.38(1.13-1.68)$ \\
\hline Post-primary & $745 / 1387$ & 53.7 & $4.73(3.72-6.00)$ & $3.4 \quad(2.63-4.38)$ & $483 / 1125$ & 43.0 & $2.26(1.79-2.85)$ & $1.94(1.52-2.49)$ \\
\hline \multicolumn{9}{|c|}{ Non-marital relations } \\
\hline None & $3158 / 8998$ & 35.1 & 1.00 & 1.00 & $1901 / 7731$ & 24.6 & 1.00 & 1.00 \\
\hline Female only & $86 / 169$ & 50.9 & $1.91(1.38-2.64)$ & $2.02(1.44-2.84)$ & $54 / 137$ & 39.4 & $2.0 \quad(1.38-2.89)$ & $1.92(1.31-2.81)$ \\
\hline Male or both & $855 / 1324$ & 64.6 & $3.37(2.95-3.84)$ & $3.33(2.91-3.81)$ & $1271 / 1740$ & 73.1 & $8.31(7.31-9.44)$ & $8.61(7.52-9.86)$ \\
\hline \multicolumn{9}{|c|}{ Co-resident biological children } \\
\hline 0 & $158 / 904$ & 17.5 & 1.00 & 1.00 & $280 / 1026$ & 27.3 & 1.00 & 1.00 \\
\hline $1-2$ & $1348 / 3598$ & 37.5 & $2.83(2.30-3.48)$ & $2.39(1.91-2.98)$ & $1210 / 3460$ & 35.0 & $1.43(1.20-1.70)$ & $1.38(1.13-1.67)$ \\
\hline $3-5$ & $2091 / 4700$ & 44.5 & $3.78(3.07-4.66)$ & $3.02(2.42-3.78)$ & $1395 / 4004$ & 34.8 & $1.42(1.20-1.69)$ & $1.45(1.19-1.76)$ \\
\hline $6+$ & $502 / 1280$ & 39.2 & $3.05(2.39-3.89)$ & $2.59(1.98-3.40)$ & $342 / 1120$ & 30.5 & $1.17(0.94-1.46)$ & $1.45(1.12-1.87)$ \\
\hline \multicolumn{9}{|l|}{ Couple HIV } \\
\hline$M-F-$ & $3522 / 9119$ & 38.6 & 1.00 & 1.00 & $2447 / 8044$ & 30.4 & 1.00 & 1.00 \\
\hline $\mathrm{M}+\mathrm{F}+$ & 289/641 & 45.1 & $1.3 \quad(1.07-1.59)$ & $1.57(1.28-1.93)$ & $392 / 744$ & 52.7 & $2.55(2.14-3.03)$ & $3.08(2.54-3.73)$ \\
\hline $\mathrm{M}-\mathrm{F}+$ & $118 / 322$ & 36.7 & $0.92(0.70-1.21)$ & $1.14(0.87-1.50)$ & $158 / 362$ & 43.7 & $1.77(1.38-2.28)$ & $2.17(1.65-2.86)$ \\
\hline $\mathrm{M}+\mathrm{F}-$ & $170 / 400$ & 42.5 & $1.17(0.91-1.51)$ & $1.4(1.08-1.80)$ & $230 / 460$ & 50.0 & $2.29(1.85-2.83)$ & $2.76(2.18-3.50)$ \\
\hline \multicolumn{9}{|c|}{ Duration between most recent female VCT and interview (days) } \\
\hline $\begin{array}{l}\text { No VCT } \\
\text { within } 30 \\
\text { days }\end{array}$ & $684 / 1961$ & 34.9 & 1.0 & 1.0 & $582 / 1859$ & 31.3 & 1.0 & 1.0 \\
\hline $31-182$ & $251 / 892$ & 28.1 & $0.73(0.61-0.88)$ & $0.84(0.69-1.02)$ & $244 / 885$ & 27.6 & $0.84(0.70-1.00)$ & $0.95(0.78-1.16)$ \\
\hline $183-365$ & $643 / 1682$ & 38.2 & $1.16(1.00-1.34)$ & $1.18(1.01-1.37)$ & $507 / 1546$ & 32.8 & $1.07(0.92-1.24)$ & $1.15(0.98-1.36)$ \\
\hline $366+$ & $2521 / 5947$ & 42.4 & $1.37(1.22-1.55)$ & $1.13(1.00-1.29)$ & $1894 / 5320$ & 35.6 & $1.21(1.07-1.37)$ & $1.15(1.00-1.32)$ \\
\hline \multicolumn{9}{|c|}{ Stage of HIVC programme roll-out } \\
\hline Pre-HIVC & $986 / 3393$ & 29.1 & 1.00 & 1.00 & $913 / 3320$ & 27.5 & 1.00 & 1.00 \\
\hline HIVC roll-out & $935 / 2464$ & 38.0 & $1.49(1.34-1.66)$ & $1.22(1.09-1.38)$ & $517 / 2046$ & 25.3 & $0.89(0.79-1.01)$ & $0.83(0.72-0.95)$ \\
\hline HIVC scale-up & $2178 / 4625$ & 47.1 & $2.17(1.96-2.41)$ & $1.77(1.58-1.99)$ & $1797 / 4244$ & 42.3 & $1.94(1.74-2.15)$ & $1.96(1.73-2.22)$ \\
\hline
\end{tabular}

${ }^{*}$ Adjusted for socioeconomic status, religion, couple's difference in age (0-4, 5-9 or 10+ years), type of marriage (monogamous or polygamous). adjOR, adjusted odds ratio; Cl, confidence interval; HC, hormonal contraception; HIVC, HIV care; OR, odds ratio; unadjOR, unadjusted odds ratio; VCT, voluntary counselling and testing. 
$36.4 \%$ and $25.0 \%$, respectively; $p=0.32$ ). Use of condoms also increased overall, $(21.2 \%, 17.3 \%$ and $28.0 \%$, respectively; $p<0.001)$ and among concordantly infected couples $(30.3 \%, 24.4 \%$ and $48.0 \%$, respectively; $p<0.001$ ), and serodiscordant couples, $(24.2 \%, 22.7 \%$ and $48.7 \%$, respectively; $p<0.001)$, but not among concordant HIV-negative couples (28.1\%, 16.3\% and 24.2\%; $p<0.001)$. Dual use of $\mathrm{HC}$ and condoms was reported by both females and males $(3.7 \%$ and $8.3 \%$, respectively; $p<0.001)$. Over the three HIVC periods, dual use increased overall for both females $(0.7 \%, 1.78 \%$ and $6.63 \% ; p<0.001)$ and males $(5.3 \%, 6.4 \%$ and $11.5 \% ; p<0.001)$ and this increase was seen irrespective of HIV status.

In addition to the variables summarised in Table 1, about three-quarters of the couples were Christians, were in a monogamous union and most couples were either in the high or the middle SES category, but no significant differences were observed by couples' HIV status.

Table 2 summarises determinants of contraceptive use among all couples in our study. Factors significantly associated with increased use of $\mathrm{HC}$ and condoms included higher levels of education, reported non-marital relations by the female, male or both, and having any co-resident biological children. When stratified by HIV status, HC use was higher among couples where the male was HIV-positive $(\mathrm{M}+\mathrm{F}+$ or $\mathrm{M}+\mathrm{F}-$ ) whereas condom use was higher if at least one member was HIV-positive relative to concordant negative couples. Duration of 6 months or more since receipt of VCT by the female partner was also associated with increased use of HC, as was HIV roll-out $\operatorname{adjOR}=1.22 \quad(95 \%$ CI $1.09-1.38)$ and scale-up adjOR $=1.77 \quad(95 \%$ CI $1.58-1.99)$ relative to the pre-HIVC period. Use of condoms increased with duration since receipt of VCT of 1 year or more, as well in the HIVC scale-up (adjOR $=1.96,95 \%$ CI 1.73-2.22), whereas there was a decrease in condom use during the HIVC roll-out period.

In order to assess the effect of enrolment into HIVC, a sub-analysis was conducted among concordant HIV-positive couples (Table 3). Factors associated with increased HC use were the male's report of nonmarital partners, having any co-resident biological children, and both partners being enrolled into HIVC.

Table 3 Odds ratios of hormonal contraception and condom use among HIV-positive concordant couples

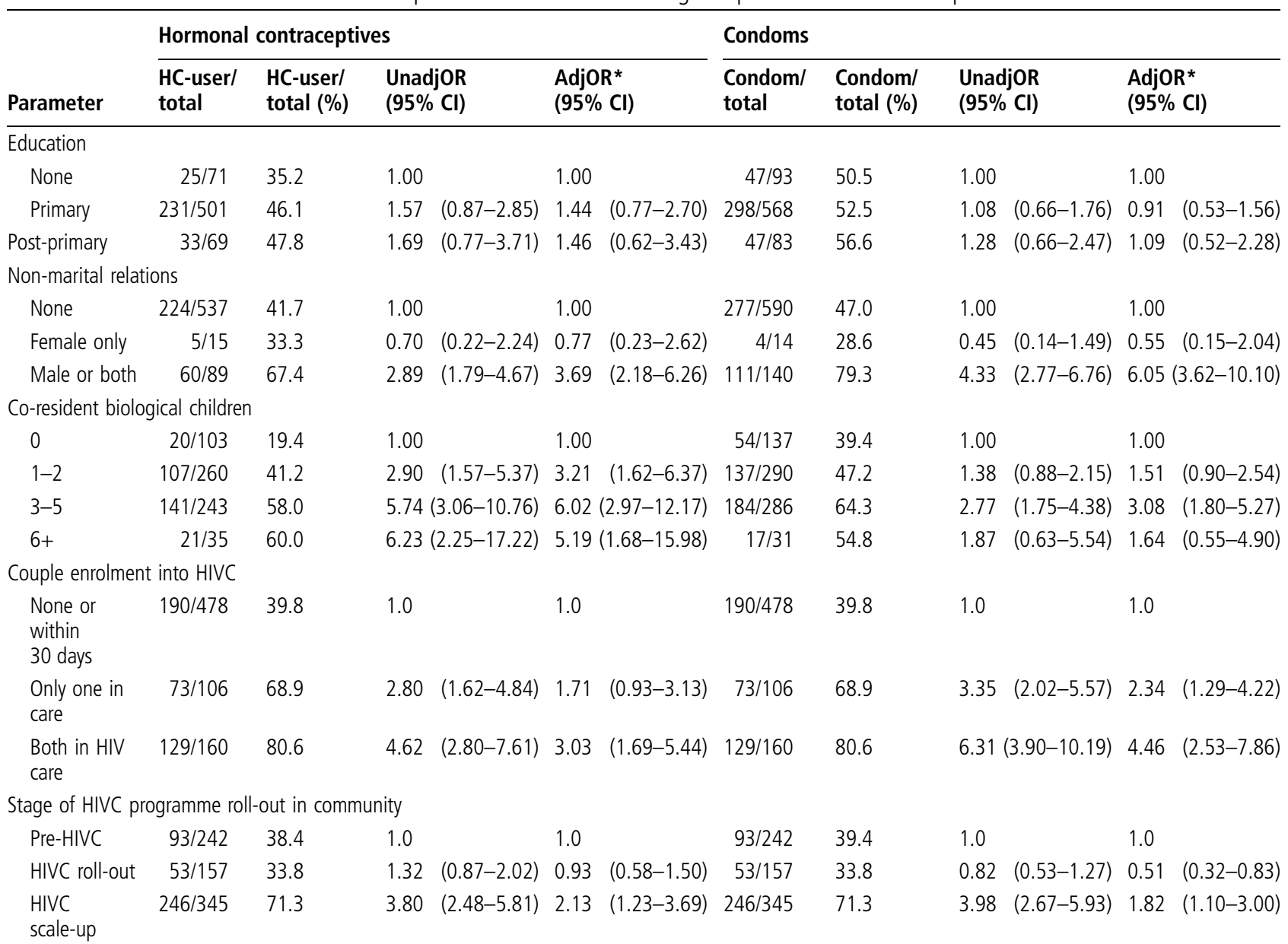

${ }^{*}$ Adjusted for socioeconomic status, religion, couple's difference in age (0-4, 5-9 or 10+ years), type of marriage (monogamous or polygamous). adjOR, adjusted odds ratio; $\mathrm{Cl}$, confidence interval; HC, hormonal contraception; HIVC, HIV care; OR, odds ratio; unadjOR, unadjusted odds ratio. 
HIVC scale-up was also associated with increase in $\mathrm{HC}$ use (adjOR $=2.13$; 95\% CI 1.23-3.69). Condom use increased with male report of non-marital partners, having any co-resident biological children, either or both partners being enrolled into HIVC and the expanded HIVC phase (adjOR $=1.82$, 95\% CI 1.13.0). Again, the roll-out phase of HIVC was associated with a decrease in condom use.

Table 4 summarises the odds of $\mathrm{HC}$ and condom use among HIV serodiscordant couples.

HC use was higher with higher education levels, report of a non-marital partner by either spouse, any co-resident biological children, and when the HIV+ spouse was enrolled in HIVC (adjOR $=2.21,95 \%$ CI $1.25-3.92)$.

Increased use of HC was observed during the HIV care roll-out and scale-up periods. Use of condoms significantly increased with post-primary education, male spouse report of non-marital partners, having more than three co-resident biological children, and almost five-fold higher odds of condom use if the HIV+ partner was enrolled in HIVC. Expanded HIVC was also associated with an increase in condom use.
Being of low or middle SES relative to high SES was associated with decreased use of HCs and condoms, irrespective of the HIV status of the couple.

Figure 1 summarises the impact of roll-out and scale-up of HIVC on contraceptive use. HC increased steadily during all the three HIVC periods among the concordant $\mathrm{M}-\mathrm{F}-$ and $\mathrm{M}+\mathrm{F}+$. However, a decline in HC was observed during the scale-up period among discordant couples $(\mathrm{M}-\mathrm{F}+, \mathrm{M}+\mathrm{F}-)$ at the time when use of condoms increased among these couples. Although use of condoms declined between the pre-HIVC and HIV-roll-out at a time when HC use increased, there was an overall increase in condom use between HIVC roll-out and scale-up periods.

\section{DISCUSSION}

Few studies prospectively assess contraceptive use among couples, despite changes in contraceptive use over time and the significant role of males in contraceptive decision-making. We longitudinally assessed contraceptive use among couples in Rakai, Uganda, adjusting for HIV-associated risk factors and HIV serostatus. Overall, almost half the couples in our study

Table 4 Odds ratios of hormonal contraception and condom use among HIV serodiscordant couples

\begin{tabular}{|c|c|c|c|c|c|c|c|c|}
\hline \multirow[b]{2}{*}{ Parameter } & \multicolumn{4}{|c|}{ Hormonal contraceptives } & \multicolumn{4}{|l|}{ Condoms } \\
\hline & $\begin{array}{l}\text { HC-user/ } \\
\text { total }\end{array}$ & $\begin{array}{l}\text { HC-user/ } \\
\text { total (\%) }\end{array}$ & $\begin{array}{l}\text { UnadjoR } \\
(95 \% \mathrm{Cl})\end{array}$ & $\begin{array}{l}\text { AdjOR* } \\
(95 \% \mathrm{Cl})\end{array}$ & $\begin{array}{l}\text { Condom/ } \\
\text { total }\end{array}$ & $\begin{array}{l}\text { Condom/ } \\
\text { total (\%) }\end{array}$ & $\begin{array}{l}\text { UnadjOR } \\
(95 \% \mathrm{Cl})\end{array}$ & $\begin{array}{l}\text { AdjOR* } \\
(95 \% \mathrm{Cl})\end{array}$ \\
\hline \multicolumn{9}{|l|}{ Education } \\
\hline None & $14 / 74$ & 18.9 & 1.0 & 1.0 & $47 / 107$ & 43.9 & 1.0 & 1.0 \\
\hline Primary & $242 / 581$ & 41.7 & $3.06 \quad(1.60-5.84)$ & $2.90(1.45-5.79)$ & $295 / 634$ & 46.5 & $1.11(0.66-1.87)$ & $1.44(0.79-2.64)$ \\
\hline Post-primary & $32 / 67$ & 47.8 & $3.92 \quad(1.69-9.11)$ & $3.50(1.42-8.60)$ & $46 / 81$ & 56.8 & $1.68(0.80-3.50)$ & $2.61(1.14-6.00)$ \\
\hline \multicolumn{9}{|c|}{ Non-marital relations } \\
\hline None & 213/609 & 35.0 & 1.0 & 1.0 & $266 / 662$ & 40.2 & 1.0 & 1.0 \\
\hline Female only & 13/19 & 68.4 & $4.03(1.46-11.08)$ & $4.62(1.51-14.11)$ & $10 / 16$ & 62.5 & $2.48(0.95-6.47)$ & $2.38(0.79-7.15)$ \\
\hline Male or both & $62 / 94$ & 66.0 & $3.60 \quad(2.22-5.85)$ & $3.59 \quad(2.18-5.91)$ & $112 / 144$ & 77.8 & $5.21(3.36-8.09)$ & $7.10(4.38-11.49)$ \\
\hline \multicolumn{9}{|c|}{ Co-resident biological children } \\
\hline 0 & $16 / 110$ & 14.6 & 1.0 & 1.0 & $50 / 144$ & 34.7 & 1.0 & 1.0 \\
\hline $1-2$ & $107 / 280$ & 38.2 & $3.63 \quad(1.86-7.11)$ & $3.03(1.53-6.00)$ & $135 / 308$ & 43.8 & $1.47(0.90-2.40)$ & $1.44(0.82-2.54)$ \\
\hline $3-5$ & $141 / 275$ & 51.3 & $6.18(3.16-12.10)$ & $4.76 \quad(2.38-9.52)$ & $163 / 297$ & 54.9 & $2.29(1.41-3.70)$ & $1.85(1.05-3.07)$ \\
\hline $6+$ & $24 / 57$ & 42.1 & $4.27 \quad(1.84-9.93)$ & $4.06(1.56-10.57)$ & $40 / 73$ & 54.8 & $2.28(1.19-4.35)$ & $2.51(1.10-5.70)$ \\
\hline \multicolumn{9}{|l|}{ Couple HIV status } \\
\hline $\mathrm{M}-\mathrm{F}+$ & $118 / 322$ & 36.7 & 1.0 & 1.0 & $158 / 362$ & 43.7 & 1.0 & 1.0 \\
\hline $\mathrm{M}+\mathrm{F}-$ & $170 / 400$ & 42.5 & $1.28 \quad(0.89-1.84)$ & $1.34 \quad(0.90-1.99)$ & $230 / 460$ & 50.0 & $1.29(0.94-1.78)$ & $1.38(0.94-2.04)$ \\
\hline \multicolumn{9}{|c|}{ Couple enrolment into HIVC } \\
\hline $\begin{array}{l}\text { HIV+ not in } \\
\text { care/within } 30 \\
\text { days }\end{array}$ & $221 / 605$ & 36.5 & 1.0 & 1.0 & $222 / 606$ & 36.6 & 1.0 & 1.0 \\
\hline $\begin{array}{l}\text { HIV+ spouse in } \\
\text { care }\end{array}$ & $67 / 117$ & 57.3 & $2.33 \quad(1.45-3.74)$ & $2.21 \quad(1.25-3.92)$ & $166 / 216$ & 76.9 & $5.74(3.82-8.62)$ & $4.75(2.89-7.82)$ \\
\hline \multicolumn{9}{|c|}{ Stage of HIVC programme roll-out in community } \\
\hline Pre-HIVC & $83 / 295$ & 28.1 & 1.0 & 1.0 & $94 / 306$ & 30.7 & 1.0 & 1.0 \\
\hline HIVC roll-out & $80 / 170$ & 47.1 & $2.27 \quad(1.49-3.46)$ & $1.86(1.20-2.90)$ & $50 / 140$ & 35.7 & $1.25(0.82-1.91)$ & $0.97(0.61-1.54)$ \\
\hline HIVC scale-up & $125 / 257$ & 48.6 & $2.42 \quad(1.62-3.62)$ & $1.79(1.12-2.88)$ & $244 / 376$ & 64.9 & $4.17(2.92-5.95)$ & $2.39(1.52-3.74)$ \\
\hline
\end{tabular}




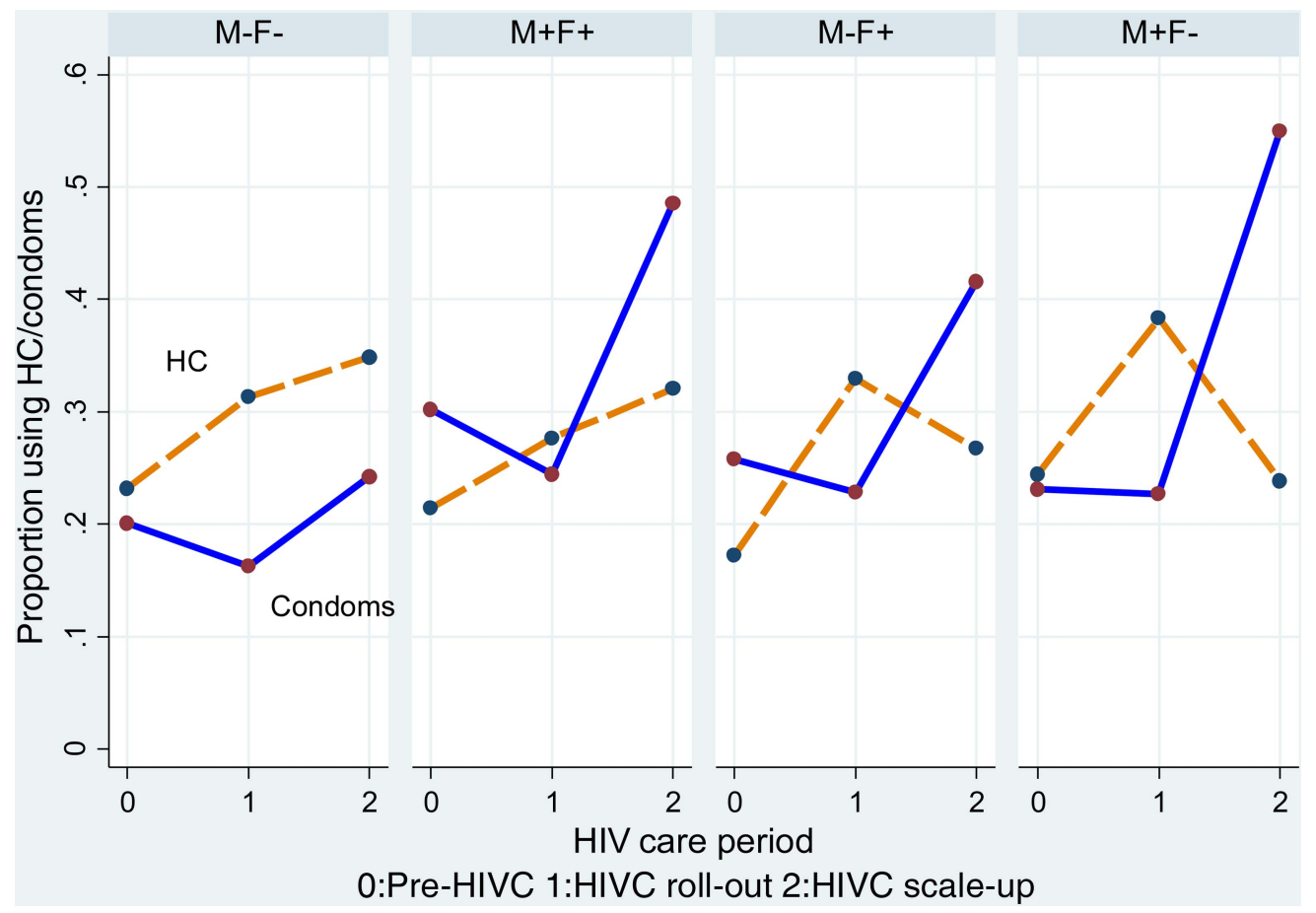

Figure 1 Trends in couples' hormonal contraception (HC) and condom use by HIV care (HIVC) roll-out period.

reported using $\mathrm{HC}$ or condoms, and as reported in other studies, ${ }^{11}{ }^{12}$ contraceptive use increased over time. Both $\mathrm{HC}$ and condom use increased significantly as HIVC was being scaled-up in the communities, and among couples where at least one member was HIV-positive, enrolment into HIVC was also associated with a significant increase in $\mathrm{HC}$ and condom use.

Several studies have assessed determinants of modern contraceptive use. ${ }^{11} 13-15$ Our findings are consistent with other studies that report contraceptive use is higher among the more educated. ${ }^{13} \quad 14 \quad 16 \quad 17$ However, we observed no impact of education on contraceptive use among HIV-positive concordant couples. Potentially, knowledge of HIV status and the desire to prevent infant infection mitigated the education effect among HIV-positive concordant couples. As with other studies, ${ }^{16}$ number of co-resident children was strongly associated with use of contraception and highlights the importance of promoting long-term effective methods for couples with two or more children, given the persistently high TFR in Uganda. ${ }^{18-21}$ Couples reporting extramarital relationships were motivated to use $\mathrm{HC}$ or condoms, especially if the male reported extramarital relationships, potentially to reduce the risk of both HIV and unwanted pregnancies when engaging in high-risk behaviours.

A longitudinal study of serodiscordant couples from seven southern and east African countries found an increase in HIV acquisition and transmission among serodiscordant couples where the woman was using HC, particularly depot medroxyprogesterone acetate. $^{22}$ However, the current WHO guidelines recommend that women at high risk for HIV infection can use HC without restriction, but advise concomitant use of condoms. ${ }^{23}$ The use of HC, and especially injectable contraceptives, is gaining popularity in SSA, especially among young women. ${ }^{24}$ In Uganda, the latest DHS reported that approximately $34 \%$ of women reported ever-use of HC. ${ }^{25}$ The significant temporal increase of $\mathrm{HC}$ use, particularly injectables among HIV-positive concordant and serodiscordant couples in our cohort, demonstrates the increasing popularity of injectable contraceptives to space or limit fertility.

Among couples where one or both partners were HIV-positive, over half (53\%) were in serodiscordant relationships. Given the high rates of HIV transmission among serodiscordant couples, ranging from 2.0 to $11.8 / 100$ person years, ${ }^{26-28}$ and that almost $20 \%$ of couples in concordant HIV-positive relationships report extramarital relationships, condom use needs to be vigorously promoted to prevent HIV transmission. Dual use of HC and condoms among couples increased significantly over time, irrespective of the HIV status of the couple, but still is infrequently practised.

All HIV-positive individuals who received HIV-positive results were counselled and invited to enrol into the Rakai HIV Care services. ${ }^{29}$ Enrolment of the HIV-positive spouse into HIVC resulted in an increase in $\mathrm{HC}$ and condom use among serodiscordant HIV-positive concordant couples. This demonstrates the importance of promoting contraceptive use in HIVC programmes, which can be important venues to integrate reproductive health and FP messages. 
A limitation of this study is that contraceptive use of the partner was self-reported but there was no specific information on which partner the respondent was referring to, especially with individuals who reported multiple sexual partners.

\section{CONCLUSIONS}

Prevention of HIV and unwanted pregnancies among couples requires a combination of strategies, including counselling about consistent condom use, contraceptive use, ART and pre-exposure prophylaxis for prevention of transmission to the uninfected partner and ART for prevention of PMTCT. Use of contraceptives among couples in our study increased over time, especially during the expanded HIVC programme in this community. Enrolment into HIVC was a determinant of $\mathrm{HC}$ and condom use, and there is a need for integration of HIV and reproductive health services so as to reduce the burden of HIV/STIs and unwanted pregnancies among women in developing countries.

\section{Author affiliations}

${ }^{1}$ Assistant Professor, Department of Population, Reproductive and Family Health, Johns Hopkins Bloomberg School of Public Health, Baltimore, MD, USA

${ }^{2}$ Lecturer, Makerere University, School of Public Health, Kampala, Uganda and Associate Professor, Population, Reproductive and Family Health, Johns Hopkins Bloomberg School of Public Health, Baltimore, MD, USA

${ }^{3}$ Senior Researcher, Rakai Health Science Program, Entebbe, Uganda

${ }^{4}$ Statistician, Rakai Health Science Program, Entebbe, Uganda

${ }^{5}$ Professor, Makerere University, School of Public Health, Kampala, Uganda

${ }^{6}$ Professor, Department of Epidemiology, Johns Hopkins Bloomberg School of Public Health, Baltimore, MD, USA ${ }^{7}$ Professor, Department of Epidemiology, Johns Hopkins Bloomberg School of Public Health, Baltimore, MD, USA

Funding National Institutes of Health (NINR:

5R01NR011474-03), Bill and Melinda Gates Foundation, Grant \# 22006.03, Grants \#U1AI51171 and

1UO1AI075115-O1A1 from the National Institutes of Health, Division of Allergy and Infectious Diseases.

\section{Competing interests None.}

Ethics approval This study was approved by Institutional Review Boards in Uganda (the Scientific and Ethics Committee of the Uganda Virus Research Institute, and the Uganda National Council of Science and Technology), and the USA (Western IRB, Olympia, Washington, and the Johns Hopkins University, School of Public Health).

Provenance and peer review Not commissioned; externally peer reviewed.

Open access This is an Open Access article distributed in accordance with the Creative Commons Attribution Non Commercial (CC BY-NC 3.0) license, which permits others to distribute, remix, adapt, build upon this work noncommercially, and license their derivative works on different terms, provided the original work is properly cited and the use is non-commercial. See: http://creativecommons.org/licenses/by$\mathrm{nc} / 3.0 /$

\section{REFERENCES}

1 World Bank. World Development Indicators. Washington, DC: World Bank; 2009.

2 United Nations Population Division. World Contraceptive Use. New York: United Nations Department of Economic and Social Affairs; 2009.

3 Statistics Department Ministry of Finance and Economic Planning. Uganda Demographic and Health Survey: 2011. Calverton, MD, USA: Macro International Inc.; 2012.

4 Statistics Department Ministry of Finance and Economic Planning. Uganda Demographic and Health Survey: 2005/6. Calverton, MD, USA: Macro International Inc.; 2007.

5 UNAIDS. AIDS Epidemic Update. Geneva, Switzerland: UNAIDS; 2011.

6 Minister of Health U. Uganda AIDS Indicator Survey 2011. Kampala, Uganda: Minister of Health; 2012.

7 Trends in HIV Rates, Behaviors, and Use of Interventions in a Population-based Cohort: Rakai, Uganda, 1994 to 2010. 19th Conference on Retroviruses and Opportunistic Infections, Seattle, Washington, 2012.

8 Wawer MJ, Sewankambo NK, Serwadda D, et al. Control of sexually transmitted diseases for AIDS prevention in Uganda: a randomised community trial. Rakai Project Study Group [see comments]. Lancet 1999;353:525-535.

9 Makumbi F, Nakigozi G, Lutalo T, et al. Use of HIV-related services and modern contraception among women of reproductive age, Rakai, Uganda. Afr J Reprod Health 2010;14:91-101.

10 Matovu JK, Kigozi G, Nalugoda F, et al. The Rakai Project counselling programme experience. Trop Med Int Health 2002; 7:1064-1067.

11 Heffron R, Were E, Celum C, et al. A prospective study of contraceptive use among African women in HIV-1 serodiscordant partnerships. Sex Transm Dis 2010;37:621-628.

12 Stephenson R, Vwalika B, Greenberg L, et al. A randomized controlled trial to promote long-term contraceptive use among HIV-serodiscordant and concordant positive couples in Zambia. J Womens Health (Larchmt) 2011;20:567-574.

13 Agyei WK, Migadde M. Demographic and sociocultural factors influencing contraceptive use in Uganda. J Biosoc Sci 1995;27:47-60.

14 Eisenberg DL, Allsworth JE, Zhao Q, et al. Correlates of dual-method contraceptive use: an analysis of the national survey of family growth (2006-2008). Infect Dis Obstet Gynecol 2012;2012:717163.

15 Magadi MA, Curtis SL. Trends and determinants of contraceptive method choice in Kenya. Stud Fam Plann 2003;34:149-159.

16 Wang C. Trends in contraceptive use and determinants of choice in China: 1980-2010. Contraception 2011; 85;570-579.

17 Calazans G, Araujo TW, Venturi G, et al. Factors associated with condom use among youth aged 15-24 years in Brazil in 2003. AIDS 2005;19(Suppl. 4):S42-S50.

18 Uganda Bureau of Statistics (UBOS), ORC Macro. Uganda-Demographic and Health Survey 2000-2001. Calverton, MD: UBOS and ORC Macro; 2001.

19 Uganda Bureau of Statistics (UBOS), Macro International Inc. Uganda Demographic and Health Survey, 2006. Calverton, MD, USA: UBOS and Macro International Inc.; 2007. 
20 Uganda Bureau of Statistics (UBOS), ORC Macro. Uganda Demographic and Health Survey, 1988-89. Calverton, MD: UBOS and ORC Macro; 1990.

21 Uganda Bureau of Statistics (UBOS), ORC Macro. Uganda Demographic and Health Survey, 1995. Calverton, MD: UBOS and ORC Macro; 1997.

22 Heffron R, Donnell D, Rees H, et al. Use of hormonal contraceptives and risk of HIV-1 transmission: a prospective cohort study. Lancet Infect Dis 2012;12:19-26.

23 World Health Organization. Hormonal Contraception and HIV: Technical Statement. 2012. http://whqlibdoc.who.int/hq/ 2012/WHO_RHR_12.08_eng.pdf [accessed 10 May 2013].

24 Creanga AA, Gillespie D, Karklins S, et al. Low use of contraception among poor women in Africa: an equity issue. Bull World Health Organ 2011;89:258-266.
25 Department of Health MRC. South Africa Demographic and Health Survey 2003. Pretoria, South Africa: OrcMacro; 2007.

26 Celum C, Wald A, Lingappa JR, et al. Acyclovir and transmission of HIV-1 from persons infected with HIV-1 and HSV-2. N Engl J Med 2010;362:427-439.

27 Quinn TC, Wawer MJ, Sewankambo N, et al. Viral load and heterosexual transmission of human immunodeficiency virus type 1. Rakai Project Study Group. N Engl J Med 2000;342:921-929.

28 Gray RH, Kiwanuka N, Quinn TC, et al. Male circumcision and HIV acquisition and transmission: cohort studies in Rakai, Uganda. Rakai Project Team. AIDS 2000;14:2371-2381.

29 Nakigozi G, Makumbi F, Reynolds S, et al. Non-enrollment for free community HIV care: findings from a populationbased study in Rakai, Uganda. AIDS Care 2011;23:764-770. 